\title{
POBREZA Y FORMACIÓN RELIGIOSA EN LA DIÓCESIS DE LEÓN DURANTE LA EDAD MODERNA
}

\author{
POR \\ ALFREDO MARTín GARCíA* \\ Universidad de León \\ aamarg@unileon.es
}

\section{RESUMEN}

El seminario conciliar de San Froilán en León nació a comienzos del siglo XVII en el contexto del empuje reformista auspiciado por el concilio de Trento. A medida que el centro adquiría reputación y rentas, sobre todo a partir del último tercio del siglo XVIII, fue perdiendo paulatinamente su carácter asistencial como espacio de acogida de estudiantes pobres para convertirse en una institución educativa de alto nivel vinculada a la Universidad de Valladolid.

PALABRAS CLAVE: Seminario; formación religiosa; León; Edad Moderna.

\section{POVERTY AND RELIGIOUS EDUCATION IN THE DIOCESE OF LEON IN THE EARLY MODERN PERIOD}

\begin{abstract}
The conciliar seminary of San Froilan in León emerged in the early seventeenth century in the context of the push for reform prompted by the Council of Trent. As the centre acquired a reputation and an income, especially from the last third of the eighteenth century onwards, it gradually lost its welfare focus as a house of refuge for poor students to become a high-level educational institution linked to the University of Valladolid.
\end{abstract}

KEY WORDS: Seminary; religious education; Leon; Early Modern Period.

$\begin{array}{ll}\text { Recibido/Received } & 21-06-2013 \\ \text { Aceptado/Accepted } & 28-07-2014\end{array}$

LA REFORMA TRIDENTINA EN LA DIÓCESIS DE LEÓN: EL NACIMIENTO DEL SEMINARIO DE SAN FROILÁN

Dejando al lado la existencia de antecedentes más o menos próximos, los seminarios nacieron como instrumentos diseñados por Trento para hacer frente al complejo asunto de la formación del clero. A la confianza depositada por los padres conciliares en la educación como agente activo del ambicioso programa reformista diseñado, se añadía la necesidad de crear instituciones ex profeso para la formación de futuros clérigos alejadas de las tentaciones del mundo y más proclives al desarrollo del proceso de disciplina interno que

* Este trabajo forma parte del proyecto de investigación titulado "Marginación y asistencia social en el Noroeste de la Península Ibérica durante el Antiguo Régimen", subvencionado por el Ministerio de Ciencia e Innovación (Ref. HAR 2010-17780). Agradezco al rector de seminario de San Froilán D. José Sánchez González, todas las facilidades dadas para el vaciado de la documentación custodiada en su archivo. se pretendía acometer. ${ }^{1}$ Aunque nunca se vinculó la estancia en estos centros a la ordenación sacerdotal, el apoyo por parte de las autoridades diocesanas y civiles, concienciadas de la necesidad de su existencia, potenció su expansión. ${ }^{2}$

En el caso específico leonés no hubo que esperar mucho tiempo tras la aprobación de las disposiciones conciliares para que se vislumbraran los primeros intentos fundacionales, amparados en un contexto especialmente proclive: el reinado de Felipe II. En junio de 1582, el obispo D. Francisco

1 Barreiro Mallón, B. 2003. "Clero secular e estudiantes na diócese de Santiago durante o século XVIII". Revista Galega do Ensino 36: 81-115, 81; García Cárcel, R. y Palau i Orta, J. 2006. "Reforma y Contrarreforma católicas", en A. L. Cortés Peña (Coord.), Historia del Cristianismo III. El Mundo Moderno: 187-226, 215.

2 Mas Galvañ, C. 2004. "Tres seminarios españoles del Setecientos: Reformismo, Ilustración y Liberalismo". Cuadernos de Historia Moderna. Anejos 3: 163-200, 165. 
Trujillo (1578-1592) informaba al cabildo catedralicio de su intención de fundar un centro "donde se sustenten y alimenten personas pobres que sean dedicadas para el ministerio de la Iglesia". ${ }^{3}$ Sin embargo, y como también sucedió en otras diócesis peninsulares, fueron los propios capitulares los que con mayor fuerza se opusieron a esa pretensión, temerosos de ver reducidas las rentas que disfrutaban. ${ }^{4}$ Este choque de intereses provocó un largo enfrentamiento que acabó enfangando los planes del prelado hasta hacerlos desaparecer. De hecho, es muy posible que la posterior fundación del colegio leonés en la Universidad de Alcalá se deba interpretar como la solución hallada por el obispo Trujillo ante la imposibilidad de fundar un seminario en su diócesis. ${ }^{5}$

De todos modos, sus pretensiones no cayeron en saco roto; pocos años más tarde, su sucesor, D. Juan Alonso Moscoso (1593-1603), retomó el proyecto, sentando las bases de una fundación que, no obstante, no verá la luz hasta el posterior pontificado de Fr. Andrés de Caso (1603-1607), debido a su promoción a la diócesis de Málaga. De todos modos, no hay duda de que la intervención del obispo Moscoso y su círculo familiar fue vital para la erección del seminario conciliar. Atento al fracaso que había padecido su predecesor, procuró desarrollar su proyecto sin enfrentarse directamente al cabildo catedralicio e intentó acumular los fondos suficientes para que el centro pudiese sobrevivir. Antes de partir dejó a su sucesor 2.000 ducados para que se invirtiesen en censos a este efecto. Además, su sobrino, Juan Arias de Moscoso, deán de la catedral de Málaga y antes arcediano de Valderas, se comprometió a donar tras su muerte una serie de beneficios del obispado que le había concedido su tío. ${ }^{6}$

Merced a estos mimbres, Fr. Andrés de Caso pudo acometer la empresa con ciertas garantías, dotando al centro de unas constituciones que regulaban su vida interna e incorporando nuevas rentas a fin de reforzar las donaciones de su predecesor. ${ }^{7}$ De este modo, el 31 de octubre de 1606 abría por fin sus puertas el seminario, poniéndose bajo la advocación de San Froilán patrón de la diócesis. Por entonces contaba con catorce colegiales pero era pretensión del obispo que ese número aumentase considerablemente cuando se

\footnotetext{
3 A.C.L. (Archivo catedralicio de León), Caja 267, Doc. 8.279.

Por razones muy similares a las observadas para León se produjeron tensiones, entre otras, en las diócesis de Huesca, Oviedo, Osma, Vich, Sevilla, Pamplona, Badajoz o Mallorca. De hecho, en las cortes castellanas celebradas en Madrid en 1592 se señaló como principal causa del evidente retraso en la fundación de seminarios, los conflictos entre obispos y cabildos que, por otro lado, se han de encuadrar en la reacción de los capitulares al proceso de reforzamiento del poder episcopal emanado de Trento. Fernández Conde, M. 1948. España y los seminarios tridentinos: 43-53 Madrid: CSIC/Instituto "Enrique Flórez"; Fernández Terricabras, I. 2000. Felipe II y el clero secular. La aplicación del Concilio de Trento: 291-360 Madrid: Sociedad Estatal para la Conmemoración de los Centenarios de Felipe II y Carlos V.

5 El conocido como "Colegio de León" de la Universidad de Alcalá fue fundado por él en 1586, dotándolo inicialmente con seis becas. Alonso, P. M., Casado, M. y Casado, F. J. 2004. El concilio de Trento y los colegios de las "naciones" de la Universidad de Alcalá de Henares: el Colegio Menor "De León" (1586-1843): 147 Madrid: Dykinson.

6 Se trataba en concreto de los beneficios de la iglesia parroquial de Santa Marina de la villa de Mayorga, del "hermitorio" de Nuestra Señora de Fuentes, término de Villalón, así como de los préstamos de las parroquiales de Castroponce y Villamizar. A.S.C.L. (Archivo del Seminario Conciliar de León), Libro de erección, dotación y agregación.

En concreto, en diciembre de 1606 agregaba otros 2.000 ducados procedentes de préstamos y beneficios del obispado.
}

incrementasen sus mecanismos de financiación. A pesar de estas buenas intenciones, lo cierto es que las rentas pronto se manifestaron insuficientes, lo que propició un rápido proceso de decadencia que culminó en su desaparición: entre 1613 y 1631 no se registró movimiento alguno en los libros de ingresos y gastos, señal inequívoca de la efímera vida de ese primer intento. ${ }^{8}$

\section{DE LA REFUNDACIÓN A LA DEFINITIVA CONSOLIDACIÓN: LA EVO- LUCIÓN DE LAS ENTRADAS DE COLEGIALES}

A comienzos de la década de los treinta del siglo XVII el jerónimo Fr. Gregorio de Pedrosa (1624-1633), tuvo que acometer la refundación del centro. Es muy posible que en este empeño por hacer reaparecer el seminario tuviera mucho que ver la decisión del deán de la catedral de Málaga de renunciar en vida a las rentas que disfrutaba en León en beneficio del seminario. Este incremento de los ingresos que mejoraba su precaria economía pudo dar esperanzas al prelado, si bien con prudencia, redujo el número de colegiales de nueve a ocho, con el fin de acomodar de un modo más adecuado los ingresos a los gastos. El 4 de enero de 1630 comenzaba la segunda etapa de vida del seminario, haciéndose la solemne toma de posesión del edificio nueve días más tarde. Estos primeros pasos cobraron un vivo impulso con la llegada a la silla episcopal de D. Bartolomé Santos de Risoba (1634-1649), un obispo profundamente imbuido por el espíritu tridentino y un convencido del papel que había de jugar la educación en el proceso reformista. ${ }^{9}$ En esta línea, el prelado trató de consolidar el seminario conciliar para evitar el peligro de decadencia o incluso de abandono. A tal efecto, hizo redactar unas nuevas constituciones, aprobadas en noviembre de 1646, y compró al cabildo las casas donde se hallaba situado, a fin de eliminar la sangría de sus rentas. ${ }^{10}$

La acción de los obispos Pedrosa y Santos de Risoba sentó las bases para la consolidación del centro, reestructurando su organización interna y mejorando sus ingresos. ${ }^{11}$ Sin embargo este proceso de refundación no se cerrará hasta comienzos de la década de los sesenta, cuando en

8 Por otro lado en 1631 se señalaba que "por aberse faltado a la provisión del dicho maestro y escolares y otras causas abía zesado y dejado de aberlos de algunos años a esta parte". A.S.C.L., Libro primero de ingresos y gastos del seminario de San Froilán.

9 A lo largo de su mandato en la sede legionense desarrolló una intensa labor pastoral, intentando reformar las costumbres, tanto de clérigos como de seglares. Visitó su diócesis en varias ocasiones, hizo cumplir las disposiciones conciliares en cuanto a la ordenación "in sacris" de los canónigos y racioneros de la iglesia catcaedral y celebró, en 1636, un sínodo diocesano. Risco, Fr. M. 1787. España Sagrada. Tomo XXXVI. Memorias de la Santa Iglesia esenta de León, concernientes a los cinco últimos siglos, con un copioso apéndice de concilios, escrituras y otros documentos muy útiles para la Historia particular de esta ciudad y su Iglesia, y para la general del Reyno. 155158. Madrid: En la oficina de Blas Román, Trat. LXXII, Cap. IV.

10 Los 4.000 ducados que costó la operación fueron sufragados mediante un repartimiento impuesto al clero diocesano. A.S.C.L., Libro de erección, dotación y agregación.

11 Desde 1630 -fecha de la refundación del seminario- en adelante se conserva la contabilidad sin alteración alguna. En ella se puede apreciar el incremento que experimentaron las rentas del seminario, subiendo sus ingresos de una media anual de 6.711 reales en la década 1630/39, hasta los 14.716 en el decenio 1750/59. A.S.C.L., Libro no 1 de ingresos y gastos del seminario de San Froilán. 
febrero de1662, el obispo D. Juan Bravo (1659-1662) dote al seminario con trece becas para otros tantos colegiales. ${ }^{12}$ No obstante, el centro continuó presentando muestras evidentes de debilidad en lo que tenía que ver con su financiación, lo que entorpecía el desarrollo de un programa de becas adecuado o la posibilidad de ofrecer dentro de sus muros un plan de estudios atractivo mediante la dotación de las cátedras necesarias. Esa circunstancia explica el discreto papel desempeñado en la época por el seminario y la preeminencia de otros centros formativos existentes en la ciudad, caso del colegio de los jesuitas o los estudios abiertos en los conventos mendicantes, en especial en el de Santo Domingo. ${ }^{13}$ Además, no debemos olvidar que el obispo o el cabildo catedralicio patrocinaban sendas becas en las universidades de Bolonia, Alcalá y Sigüenza ${ }^{14}$ y que las universidades de Salamanca y Valladolid se hallaban a una distancia relativamente próxima de León, lo que facilitaba los desplazamientos de estudiantes. ${ }^{15}$

Estas impresiones quedan perfectamente reflejadas en el gráfico de evolución de las entradas de colegiales. Ante la ausencia de libros de matrícula continuados para todo el periodo, hemos optado por utilizar como base de este estudio los expedientes de información de los alumnos, fuente que, como veremos, ofrece grandes posibilidades al

12 Así queda reflejado en el primer libro de informaciones del centro. A.S.C.L., Libro no 1 de informaciones.

${ }_{13}$ En el siglo XVI el regimiento leonés había solicitado al provincial de los predicadores que "pusiese en ese conbento estudio de teología", ofreciendo en compensación el privilegio para introducir en él cien carros de vino por valor de cien ducados. Aún en la década de los ochenta del siglo XVIII, los dominicos continuaban desempeñando un papel central en el mundo educativo leonés: cuando el tío de Juan Antonio Posse, el famoso "cura liberal", decidió iniciar a su sobrino en los estudios de filosofía, lo envió a dicho convento, adonde acudían un nutrido número de estudiantes, incluyendo los propios colegiales de San Froilán, que permanecían en él hasta que, concluido el año de lógica, quedaban ya bajo la dirección de sus catedráticos. A.M.L. (Archivo Municipal de León), Actas municipales, Caja 43, Libro no 18 , fol. 14 vto; Herr, R. (Ed.) 1984. Memorias del cura liberal Don Juan Antonio Posse, con su discurso sobre la constitución de 1812: 23-24 Madrid: CIS/Siglo XXI.

14 Alonso, P. M., Casado, M. y Casado, F. J. 2004. El concilio de Trento y los colegios de las "naciones" de la Universidad de Alcalá de Henares: el Colegio Menor "De León" (1586-1843): 147 Madrid: Dykinson; Villacorta Rodríguez, T. 1974. El cabildo de la catedral de León. Estudio histórico-jurídico, siglos XII-XIX: 464-477 León: Centro de Estudios e Investigación "San Isidoro".

15 Los leoneses, tanto de la diócesis de Astorga como de la de León, significaban entre el 2 y el $6 \%$ del total de estudiantes en la Universidad de Valladolid durante los siglos de la Edad Moderna, porcentajes similares a los observados en la Universidad de Salamanca entre el estudiantado manteísta. Por razones de proximidad geográfica parece que esta última fue la salida más frecuente para los astorganos mientras que los leoneses mayoritariamente se dirigieron a Valladolid. Torremocha Hernández, M. 1986. "La matriculación estudiantil durante el siglo XVIII en la Universidad de Valladolid". Investigaciones históricas: Época moderna y contemporánea 6: 39-74, 65; Sobaler Seco, Ma. A 2004. "Los estudiantes leoneses en la Universidad de Valladolid durante la Edad Moderna (ss. XVI-XVIII)", en J. Paniagua Pérez (Coord.), Hacia la Universidad de León: Estudios de Historia de la Educación en León: 193-220. León: Universidad de León; Polo Rodríguez, J. L. 1991. "Estudiantes manteístas salmantinos en la Universidad de Salamanca de la primera mitad del siglo XVIII". Studia Historica. Historia Moderna, 9: 23-41, 26; Rodríguez San Pedro Bezares, L. E., Alejo Montes, F. J. y Polo Rodríguez, J. L. 2004. "Matrículas y grados, siglos XVI-XVIII", en Rodríguez San Pedro Bezares, L. E. (Coord.), Historia de la Universidad de Salamanca: Vol. 2, 607-663. Salamanca: Universidad de Salamanca. investigador, dada la riqueza de datos que proporciona. La elaboración de estas averiguaciones, en donde debía acreditarse a través de una serie de testigos que el estudiante cumplía con todos las obligaciones intelectuales, físicas, morales, sociales y económicas exigidas por el centro, era un requisito contemplado en las diferentes constituciones que rigieron la vida interna del seminario a lo largo de los siglos de la época moderna: desde las primeras, auspiciadas por Fr. Andrés de Caso en 1606, a las redactadas en tiempos de Bartolomé Santos de Risoba (1646) o a las dieciochescas de Cayetano Cuadrillero (1792). ${ }^{16}$ Lamentablemente, y a buen seguro debido a la precaria situación que padeció esta institución educativa en sus primeras décadas de vida, el registro con el que contamos no se inicia hasta 1662. A partir de ese año disponemos ya de información continua y fiable hasta bien entrado el siglo XIX. ${ }^{17}$

El expediente se abría, una vez superado el pertinente examen, con la solicitud formal de una plaza de colegial en el seminario por parte del padre o representante del aspirante..$^{18}$ Como respuesta a esta petición, el prelado de turno, a través de su secretaría de cámara, firmaba un despacho de información, encomendando al cura párroco de la localidad de donde era vecino el estudiante la averiguación. En ella, había de recopilar una serie de testimonios que respondiesen al cuestionario fijado en las constituciones y que buscaba corroborar la idoneidad del candidato. ${ }^{19} \mathrm{~A}$ la información se le incorporaba también la partida de bautismo del aspirante y, a veces, la de matrimonio de sus padres. Finalmente, tras la certificación del notario apostólico, el obispo firmaba un mandato al rector del seminario para que aceptase al aspirante dentro del colegio. ${ }^{20}$

Para acometer el análisis evolutivo de las entradas de estudiantes, atendiendo al limitado volumen anual de las mismas en buena parte del período objeto de estudio, hemos optado por agruparlas en quinquenios, facilitándonos de este modo su análisis. Atendiendo a lo dicho, podemos marcar cinco etapas en la historia del seminario desde su refundación, a mediados del siglo XVII, hasta la caída del Antiguo Régimen (Gráfico no 1).

16 Así se estipula en el capítulo segundo de las constituciones de 1606 y 1646 y en el decimotercero de las de 1792. A.S.C.L.., Libro de erección, dotación y agregación; Libro de las constituciones del obispo Bartolomé Santos de Risoba; Real Provisión por la que se aprueban las constituciones o estatutos para el régimen y gobierno de colegio seminario de San Froilán.

17 Estos expedientes fueron posteriormente agrupados y cosidos en diferentes libros, circunstancia que, sin duda, ha facilitado su conservación. A.S.C.L. Libros de informaciones $n$ o 1-10.

18 Dicho documento ha desaparecido en buena parte de las informaciones del siglo XVII y de la primera mitad del XVIII.

19 El número de testigos - seis- se mantuvo fijo durante el período aunque las cuestiones a responder sufrieron leves variaciones que no suponían cambios significativos en la esencia de la información sino que, más bien, buscaban agilizar el proceso. A.S.C.L., Constituciones del Collegio Seminario de San Froylán desta ciudad de León hechas y ordenadas por el Sr. Obispo Fray Andrés de Caso, del Consejo de su Magestad, Cap. III; Real Provisión por la que se aprueban las constituciones o estatutos para el régimen y gobierno de colegio seminario de San Froilán. Cap. XIII.

20 Un esquema muy similar al observado en la época para otros seminarios, caso, por ejemplo, del de Burgo de Osma. Bartolomé Martínez, B., Utrilla Soria, P. y Yagüe Durán, J. 1999. “Los autos de información y pruebas de pureza de sangre de los alumnos del colegio seminario en el Burgo de Osma (1617-1851)". Celtiberia 93: 365-398, 372. 


\section{GRÁFICO 1}

Evolución de las entradas de colegiales en el seminario de San Froilán (1662-1831)

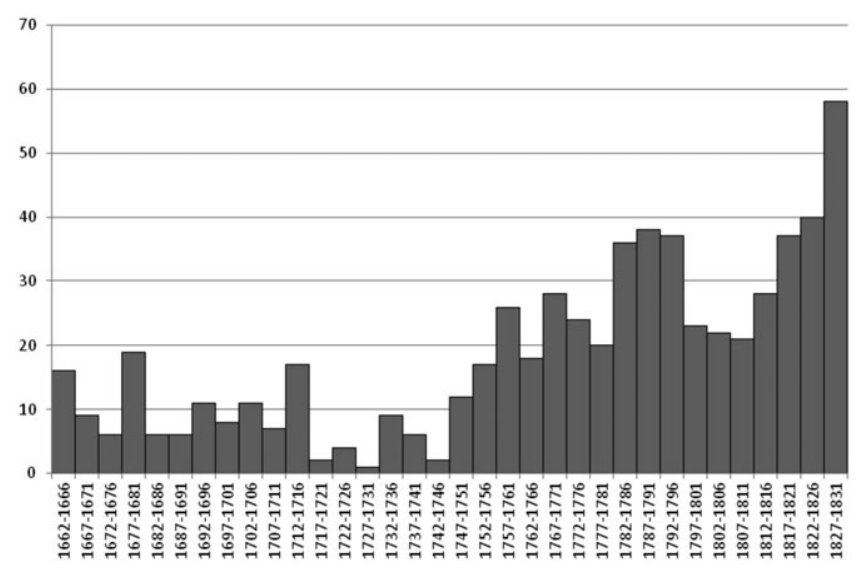

La primera de estas etapas se inicia en 1662, año en el que comienza la serie, prolongándose hasta 1716. Ciertamente, como ya hemos señalado con anterioridad, los obispos Pedrosa y Santos de Risoba, a mediados del XVII, habían logrado consolidar definitivamente el seminario, tras décadas de incertidumbre. No obstante, resulta evidente que la institución, debido fundamentalmente a las estrecheces económicas que padecía, no se había constituido en un centro educativo de referencia, ni siquiera a nivel local. Era, más bien, un simple colegio donde se recogía un reducido número de estudiantes que, en la mayoría de las ocasiones, podían, merced a la caridad de las becas, completar sus estudios en otros centros formativos de la capital, caso del colegio de los jesuitas o del convento de Santo Domingo. Durante esta primera etapa, que podemos denominar de consolidación del centro, la media anual de entradas alcanza los 2,1 alumnos, cifra ciertamente modesta que refleja las limitaciones de aquella refundación. En este espacio temporal, algunos de los sucesores de los obispos Pedrosa y Santos de Risoba, mostraron interés por mantener vivo el seminario, llevando adelante visitas o firmando providencias a fin de mejorar el funcionamiento interno, la disciplina o la calidad intelectual de los colegiales. ${ }^{21}$ Sin embargo, ninguno de ellos planteó reformas profundas que pudiesen ampliar sus capacidades formativas o el número de estudiantes becados.

Si los prelados de esa primera etapa no fueron capaces de dar ese salto cualitativo importante que pudiese convertir al seminario de San Froilán en una institución educativa de referencia, la situación todavía empeoró de un modo considerable a partir de la segunda década del siglo XVIII. Entre 1717 y 1746, su capacidad de atracción se vio reducida a la mínima expresión. Durante esos veintinueve años que constituyen la segunda etapa, la media anual de ingresos descendió a 0,8 , hallándose un número significativo de años en los que no entró ningún nuevo colegial. Esta situación de franca decadencia fue especialmente grave entre 1717 y 1731: en el quinquenio $1717-1721$ solamente tomaron

21 Sirvan como ejemplo las visitas ejecutadas en agosto de 1656 por Fr. Juan del Pozo y en diciembre de 1677 por D. Juan Álvarez de Osorio, o las providencias firmadas en 1704 por D. José Gregorio de Rojas, en 1710 por D. Manuel Pérez de Araciel o en 1716 por D. José Ulzurrun de Asanza y Civera. A.S.C.L., Libro de las constituciones del obispo Bartolomé Santos de Risoba. la beca dos estudiantes y entre 1727 y 1731 uno. A partir de entonces se aprecia una leve recuperación en los años inmediatamente posteriores, para volver a caer a niveles mediocres entre 1742 y 1746 . Las razones de esta situación de marcada crisis debemos buscarla en el escaso interés por el seminario mostrado por los obispos de la época, como atestiguan la ausencia de visitas y disposiciones de ningún tipo. Tal falta de vigilancia de lo que sucedía puertas adentro provocó asimismo el descuido por parte de los diferentes rectores en la gestión de las ya de por si limitadas rentas del centro, lo que debió de motivar un inevitable recorte en el número de colegiales admitidos. ${ }^{22}$

De la seria crisis padecida durante buena parte de la primera mitad del siglo XVIII se saldrá con fuerza a partir del quinquenio 1747-1751, experimentándose un progresivo incremento de las entradas hasta alcanzar las cotas máximas a comienzos de la década de los noventa. En efecto, si la media anual de ingresos de colegiales fue hasta 1781 de 4,3 , en el período 1782-1796 se disparó hasta alcanzar los 7,9 alumnos al año; nunca en toda la historia del centro se habían logrado unas cifras semejantes. Es evidente que en esa última aceleración tuvo mucho que ver la intensa actividad desarrollada durante aquellos tiempos por el obispo Cayetano Cuadrillero, pero no es menos cierto que antes de su llegada a la sede legionense sus antecesores habían sentado unas sólidas bases para las profundas transformaciones que viviría el seminario de la mano de aquel famoso obispo ilustrado. De hecho, los primeros pasos en la senda de la recuperación se dieron bajo el pontificado del benedictino Fr. José de Lupia y de Roger (1736-1752), hombre de innegable vocación pastoral y profundos sentimientos caritativos. ${ }^{23}$ En 1746, es decir, un año antes del cambio de tendencia en las entradas, el obispo ordenó acometer unas obras de remodelación del edificio, ${ }^{24}$ que vinieron precedidas por una callada labor de reorganización de las cuentas del seminario. ${ }^{25}$ Ambos elementos, unidos al interés del prelado por recuperar el número de becas que el centro podía ofrecer atendiendo a sus recursos, produjeron los primeros síntomas de recuperación. Esta nueva actitud positiva fue el denominador común de la mayoría de sus sucesores en la sede legionense: así lo atestiguan las huellas de esa labor

22 Si en la última década del siglo XVII, la media anual de ingresos en las arcas del seminario era de 10.071 reales, en la de los veinte del XVIII solamente alcanzaba los 7.704. Otro testimonio de esa falta de rigor en la gestión del patrimonio lo encontramos en la propia contabilidad reflejada en los libros de ingresos y gastos de la época, marcada por aquellos años por su carácter caótico y su escasa claridad. A.S.C.L., Libros de ingresos y gastos del seminario de San Froilán, no 2 y 3 .

${ }^{23}$ Durante su episcopado visitó cuatro veces la diócesis y en su testamento dividió sus bienes en tres partes: una para las iglesias pobres de la diócesis, otra para los más necesitados y una tercera para fundar una memoria perpetua en la catedral. Risco, M. 1787: 181-182.

24 En 1746 el obispo encomendaba al rector del seminario, D. Cristóbal de Villalba, la ejecución de una obra que tenía por objeto acabar con los continuos problemas de filtraciones que sufrían los tejados del edificio y que habían causado gravísimos daños "así en lo principal de sus paredes como en la desunión de maderas que forman los desbanes y tejados". Asimismo, se programó la construcción de una pequeña estancia junto a los aposentos del rector para que pudiese alojarse el paje que lo asistía. A.S.L., Libro no 4 de ingresos y gastos del seminario de San Froilán.

25 En 1739 los ingresos del colegio se limitaban a 28.200 reales, en 1741 aumentaron hasta los 34.350, alcanzando los 81.326 en 1745. A.S.L., Libros no 3 y 4 de ingresos y gastos del seminario de San Froilán. 
reformadora que han quedado reflejadas en la documentación. Desde la década de los cuarenta del siglo XVIII en adelante vuelven a aparecer visitas de los prelados al seminario y decretos que buscan enmendar errores detectados en la organización interna del centro o remediar algunas deficiencias en las instalaciones. ${ }^{26}$

Aun siendo conscientes de la meritoria labor de estos obispos, fue, sin lugar a dudas, la irrupción en la diócesis de León de la poderosa figura de D. Cayetano Antonio Cuadrillero (1778-1800) la que transformó en profundidad el seminario hasta convertirlo en un centro educativo de referencia, como demuestra la aceleración en el ritmo de las entradas que se produce en los años que coinciden, a grandes rasgos, con su gobierno. ${ }^{27}$ El prelado, que ya había destacado por su labor reformadora en la diócesis de Ciudad Rodrigo, concebía el seminario no como un mero colegio para albergue de un puñado de estudiantes pobres, sino como el instrumento más a propósito para formar un clero diocesano bien preparado, tanto en lo intelectual como en lo disciplinar. Coincidía en esta concepción con los postulados jansenistas de la época que eran los imperantes en el entorno de la corte y que, sin duda, facilitaron sobremanera la labor reformadora del obispo. En efecto, el interés de la Corona por promocionar una religiosidad más íntima y una práctica moral más rigurosa, amén de un clero sumiso a los postulados del reformismo borbónico se trató de canalizar a través de la reforma de la enseñanza. ${ }^{28}$ En este contexto la fundación de nuevos seminarios o la reestructuración de los ya existentes fue característica tanto del reinado de Carlos III como de su hijo Carlos IV. ${ }^{29}$

Amparado por esta coyuntura favorable y consternado ante "la mucha ignorancia que hay en todo el estado eclesiástico", Cuadrillero trató desde muy pronto de aplicar las medidas necesarias para potenciar el papel que había de desempeñar el seminario de San Froilán. A tal fin, buscó solucionar, o al menos mitigar en la medida de sus posibilidades, el secular problema económico del centro, dotándolo de nuevas rentas y ordenando las ya existentes mediante el nombramiento de gestores adecuados. ${ }^{30}$ Asimismo, mejoró

26 Los dos obispos inmediatamente anteriores a la llegada de Cuadrillero -D. Pascual de Herrero y D. Baltasar de Yusta y Navarroson los más activos a este respecto.

27 Sobre la labor específica de Cuadrillero en el seminario leonés Vid. Sánchez González, J. 2009. "El obispo Cuadrillero y el Seminario Conciliar de San Froilán de León”. Studium legionense. 50: 299-322.

28 Mas Galvañ, C. 2004. "Tres seminarios españoles del Setecientos: Reformismo, Ilustración y Liberalismo". Cuadernos de Historia Moderna. Anejos 3: 163-200, 168; Vergara Ciordia, J. 1997. "La actitud de la jerarquía eclesiástica ante el fenómeno de la secularización docente ilustrada", en J. Vergara Ciordia (Coord.), Estudios sobre la secularización docente en España: 61-95 Madrid: UNED, 77 y ss; Vergara Ciordia, J. 1986. "Factores condicionantes del desarrollo de los seminarios conciliares en el reinado de Carlos III", en Iglesia y educación en España. Perspectivas históricas. IV Coloquio de Historia de la Educación: 292-401 Palma de Mallorca: Universitat de les Illes Balears.

29 Durante el reinado de Carlos III se fundaron diez nuevos seminarios, reformándose la práctica totalidad de los ya existentes. Esta tendencia prosiguió en los primeros años del reinado de Carlos IV. Martín Hernández, F. y Martín Hernández, J. 1973. Los seminarios españoles en la época de la Ilustración. Ensayo de pedagogía eclesiástica en el siglo XVIII: 142 Madrid: CSIC/Instituto Enrique Flórez.

${ }_{30}$ Los ingresos anuales no dejaron de crecer desde la llegada de Cuadrillero a la sede legionense: si en 1778, año de su toma de sustancialmente las instalaciones que venían adoleciendo de no pocas deficiencias desde su erección y, lo que es más importante, proporcionó al seminario de un equipo docente adecuado con la fundación de una serie de cátedras aceptablemente dotadas, aspecto que se completó en 1790 con la incorporación de sus estudios de teología y filosofía a la Universidad de Valladolid. ${ }^{31}$

Los cambios operados tuvieron su fiel reflejo en la demanda de ingresos. El seminario de San Froilán había dejado de ser un pequeño colegio para albergue de un reducido número de estudiantes pobres, para convertirse en el principal centro de estudios superiores de la provincia de León. Las nuevas rentas concedidas no sólo garantizaron el aumento en el número de estudiantes que podían acceder a las becas, sino que también abrieron las puertas del centro a otros sectores de la sociedad leonesa que hasta entonces no habían estado interesados en él. La existencia de un programa formativo bien definido, con un cuadro docente de prestigio, y su vinculación a la Universidad de Valladolid convirtieron al seminario en una salida muy a considerar para los hijos de los sectores acomodados. En consecuencia, ya no sólo accedían a él aquellos afortunados que podían optar a la concesión de una beca, sino también otros jóvenes a los que sus familias enviaban asumiendo los gastos que reportaba su estancia. La presencia de pensionistas, es decir, de alumnos sin beca, no significaba una novedad, puesto que estaba perfectamente regulada desde las primeras constituciones de 1606. Sin embargo, su paso por el seminario fue hasta entonces meramente testimonial, como veremos más adelante, reflejo del escaso interés que suscitaba entre los sectores letrados. Fue a partir del último tercio del siglo XVIII cuando se apreció una presencia significativa de este tipo de alumnos. A ello habría que añadir los no residentes que, lamentablemente, no quedan reflejados en los expedientes de información manejados pero de cuya presencia tenemos referencias indirectas. ${ }^{32}$

La coyuntura recesiva, desde el punto de vista económico y demográfico, que vivió la provincia de León en los últimos años del siglo XVIII y comienzos del XIX, unido al impacto de la Guerra de la Independencia, frenaron este proceso de un modo bastante brusco, produciéndose un importante descenso en las entradas de estudiantes entre

posesión, el seminario recaudaba 61.684 reales, veinte años más tarde, la cantidad ya ascendía a 171.437. Este volumen de ingresos descendió un tanto en los últimos años de la centuria por efectos de la severa crisis económica del país. A.S.C.L., Libros $n$ o 7 y 8 de ingresos y gastos del seminario de San Froilán.

31 Por Real Cédula de 15 de enero de dicho año, los estudiantes del seminario -también los externos-, podían obtener los grados de bachiller, licenciado y doctor, con "el mismo valor que si hubieran sido ganados en la universidad". A.S.C.L., Reales Cédulas y provisión.

32 Sabemos de la existencia de estos alumnos externos a través de las alusiones esporádicas que se hacen en las visitas efectuadas por los obispos, las constituciones que regulan la vida interna del seminario o la correspondencia entre el rector y la máxima autoridad diocesana. También en las informaciones de los alumnos residentes pueden aparecer testimonios al respecto. En 1823, D. José Garrido, vecino de Valencia de Don Juan, solicitaba la admisión de su hijo Fidel Gregorio como colegial convictor, señalando que llevaba ya tiempo estudiando en el seminario gramática y filosofía y que juzgaba en ese momento necesario su internamiento "persuadido el que expone lo conveniente que le será para mayor adelantamiento de dicho su hijo en la virtud y en las letras". A.S.C.L., Libro no 9 de informaciones. 
1797 y $1811 .^{33}$ Aún a pesar de ello, las sólidas bases económicas asentadas por Cuadrillero y el propio prestigio adquirido por el centro mitigaron el declive. De hecho, durante este período, aún siendo evidente la caída sufrida en los ingresos, la media anual estuvo incluso por encima de la de la etapa $1747 / 1781-4,9$ frente a 4,3-.

Finalmente, tras ese período negativo, motivado más por cuestiones exógenas que endógenas, el seminario de San Froilán volvió a crecer a buen ritmo a partir del quinquenio $1812 / 16 .{ }^{34}$ En los dos siguientes se mantuvo a unos niveles muy similares a los observados en los momentos de apogeo del centro durante las últimas décadas del siglo XVIII, para después seguir incrementando los ingresos hasta alcanzar en el último lustro las cotas más elevadas de todo el marco temporal estudiado: entre 1827 y 1831 accedieron al seminario un total de 58 nuevos estudiantes, suponiendo una media anual de 11,6. La recuperación de las rentas tras los fatídicos primeros años del nuevo siglo y la incorporación de otras nuevas en 1816, merced a la labor del obispo D. Ignacio Ramón de Roda, facilitaron dicho cambio de coyuntura. ${ }^{35}$

\section{TIPOLOGÍA DE LOS COLEGIALES: POBRES Y CONVICTORES}

En el seminario se distinguían dos tipos de colegiales: los pobres, llamados en tiempos de Cuadrillero "de número", cuyos gastos principales de alimentación y vestido corrían a cuenta del centro, y los convictores o pensionistas, aquellos que, aun disfrutando de la clausura, debían sufragar dichos gastos. Las múltiples carencias que padeció el seminario hasta bien entrada la centuria dieciochesca motivó su limitado impacto entre la clientela potencial que podía interesarse por el ingreso de sus hijos en el colegio previo pago de las cuotas correspondiente (Tabla no 1). Esa circunstancia trajo consigo la preponderancia de los colegiales pobres frente a los convictores durante toda la segunda mitad del siglo XVII y la primera del XVIII, alcanzando siempre porcentajes superiores al $80 \%$. Sin embargo, cuando se acometieron las importantes reformas de la segunda mitad de aquel siglo, sobre todo a partir de la llegada del obispo Cuadrillero, el dominio de los estudiantes pobres comenzó a debilitarse, experimentándose un notable incremento, tanto en porcentaje como en cifras brutas, del número de pensionistas. A medida que nos acercamos a los últimos años de la centuria este proceso se va acelerando; así, si entre 1751 y 1780 los pobres suponían todavía el $74,4 \%$ del total de los ingresos, entre 1781 y 1800 habían ya descendido porcentualmente hasta el $55,2 \%$.

33 Pérez Álvarez, Mạ. J. 2009. "Mortalité et hygiène dans la ville de León au cours de l'époque moderne". Annales de Bretagne et des Pays de L'ouest 116-2: 55-79, 62.

34 Lo cierto es que, realizando un análisis anual y no quinquenal, se observa como el proceso de recuperación se retrasa un poco en el tiempo, iniciándose con fuerza a partir de 1816, año en el que ingresan en el seminario 13 de los 28 alumnos contabilizados para este lustro.

35 En 1816 el prelado conseguía de la Corona un decreto por el que incorporaba al centro un considerable número de beneficios simples del obispado. A.S.C.L., Escrituras de ventas.
TABLA $n$ ㅇ 1

Tipología de los estudiantes en el Seminario Conciliar de San Froilán (1662-1831)

\begin{tabular}{|l|c|c|c|c|c|}
\hline & Pobre & $\%$ & Convictor & $\%$ & Total \\
\hline $1662-1700$ & 67 & 88,2 & 9 & 11,8 & 76 \\
\hline $1701-1750$ & 54 & 80,6 & 13 & 19,4 & 67 \\
\hline $1751-1800$ & 168 & 64,9 & 91 & 35,1 & 259 \\
\hline $1801-1831$ & 56 & 26,2 & 158 & 73,8 & 214 \\
\hline TOTAL & 345 & 56,0 & 271 & 44,0 & 616 \\
\hline
\end{tabular}

A.S.C.L. Libros de informaciones

Este cambio de tendencia se aceleró drásticamente en el primer tercio del XIX, momento en el que el seminario de San Froilán dejó de ser un centro focalizado fundamentalmente a los estudiantes pobres para convertirse en una institución educativa de pago, en la que más del $73 \%$ de sus alumnos sufragaban sus estudios. No hay duda de que la aparición de las cátedras y su vinculación a la Universidad de Valladolid prestigiaron el seminario hasta el punto de convertirlo en el centro educativo de referencia a nivel diocesano o incluso provincial. ${ }^{36}$ Por otro lado, se constata una limitación en el número de estudiantes pobres admitidos. Si entre los treinta años englobados en el período 1770-1800 accedieron al seminario un total de 70 colegiales de esta naturaleza, en los posteriores (1801-1831) solamente lo hicieron 56. En resumidas cuentas, el número de estudiantes aumentó en este período sobre la base del innegable atractivo que suscitaba el seminario como centro de educación superior. Sin embargo, ese incremento redujo, al menos en parte, el cariz caritativo del mismo.

Desde luego, el recogimiento en la institución de estudiantes pobres debía ser una de sus principales funciones, siguiendo los mandatos del concilio de Trento. ${ }^{37}$ Ahora bien, el matiz se encuentra a la hora de delimitar con exactitud el concepto de pobreza. Es evidente que dadas las exigencias formativas que se estipulaban para el acceso -saber leer, escribir y los fundamentos de la doctrina cristiana-, un sector mayoritario de la población quedaba ya al margen. En las primeras constituciones del seminario, las de Fr. Andrés de Caso de 1606, se señalaba que el aspirante a la beca debía "no tener bastante hacienda para seguir los estudios ni persona que se la pueda dar". ${ }^{38}$ Pero esa imposibilidad económica no implicaba la ausencia de obligaciones por parte del entorno familiar del estudiante,

36 Sirva como ejemplo del interés mostrado en la época por muchos padres o tutores lo manifestado en 1829 por Dña. Julia Gómez, madre del pensionista Manuel María Abad. En la solicitud de ingreso de su hijo en el seminario, señalaba que, dado que a su edad, dieciséis años, "suelen principiar a extraviarse los jóvenes", había decidido internarlo en el centro para que "no se suceda alguna de aquellas desgracias que la casualidad de las malas compañías u otra igual suela proporcionarles, convencida de que en el retiro y recogimiento del seminario conciliar de esta ciudad podrá continuar con el éxito de que la madre e hijo apetecen". A.S.C.L., Libro $n$ o 9 de informaciones.

37 Martín Hernández, F. 1964. Los seminarios españoles. Historia y pedagogía I (1563-1700): 139 Salamanca: Ediciones Sígueme.

38 A.S.C.L., Libro de erección, dotación y agregación. Constituciones de Fr. Andrés de Caso, Cap. III. 
dado que el auxilio que le ofrecía el seminario tenía sus límites. ${ }^{39}$ Así, en ese primer texto normativo se especificaba que corría de cuenta de la familia del colegial la adquisición del manto, la beca, el balandrán o ropa con mangas, dos jubones de lienzo, ropilla negra con dos pares de mangas negras, dos greguescos y dos pares de medias, cuatro camisas, cuellos y puños, dos bonetes, guantes, zapatos, cuatro "lienços de nariçes" "y cama cumplida en qué dormir".40

Aunque estas obligaciones podían mitigarse a discreción del obispo, no hay duda de que la familia del colegial pobre debía asumir una serie de gastos de cierta importancia. Una vez aportado ese pequeño ajuar, el seminario se comprometía a proporcionarle vestido y calzado durante su período de estancia, atendiendo a la necesidad de cada uno, debiendo, en contraprestación, devolver al colegio aquellas piezas útiles una vez finalizada su estancia en él. Estas cargas no desaparecieron en los siglos posteriores. En 1792, las constituciones del obispo Cuadrillero, se expresaban en términos muy similares:

"Aunque deverán los de número ser pobres, no lo han de ser tanto que no tengan surtido correspondiente de ropa interior y exterior y de los libros que llevamos señalados para sus estudios, como también de cama y demás muebles que necesitan en el quarto, en lo qual se deberá poner sumo cuidado antes de admitirles". ${ }^{41}$

Tanto las exigencias culturales como económicas restringían pues sobremanera el ámbito de captación de estudiantes. En consecuencia, la supuesta pobreza de sus familias respondía, en general, a dos parámetros: o bien era consecuencia de alguna pauta demográfica más o menos trágica en el entorno doméstico del solicitante o bien provenía de las dificultades de la economía familiar para sobrellevar sin auxilio los cuantiosos gastos que suponía la formación del hijo, pudiendo producirse también con cierta frecuencia la conjunción de ambos factores. A estas conclusiones podemos llegar a través del rastro informativo que dejan las averiguaciones efectuadas a los colegiales. En ellas se nos muestran los criterios sobre los cuales justificaban los solicitantes su condición de pobres que les facultaba para ser merecedores de la concesión de una de las becas del seminario. ${ }^{42}$ Partiendo, de la prudencia con la que debemos tomar la información recogida, habida cuenta de la naturaleza de la misma y su propensión a magnificar las

39 Dichas obligaciones del entorno familiar no eran exclusivas del caso leonés pues eran moneda común en todos los centros de estas características en la época. Martín Hernández, F. 1964: 214-215.

40 A.S.C.L., Libro de erección, dotación y agregación. Constituciones de Fr. Andrés de Caso, Cap. III.

41 En concreto, Cuadrillero señalaba como ajuar necesario para todo colegial, ya fuera pobre o convictor, el siguiente: una cama con dos colchones, dos fundas de ropa blanca, dos paños de manos, una mesa, un baúl, dos sillas, un recado de escribir, unas tijeras, un peine, una jarra o unos vasos para el aseo corporal, un velón, una aceitera, un crucifijo, una imagen de la Virgen, así como los libros necesarios para los estudios. A.S.C.L., Libro de las constituciones de D. Cayetano Cuadrillero, Caps. XIII y XXV.

42 De las 345 averiguaciones referidas a estudiantes pobres contamos con 253 que aportan datos sobre esta cuestión. Los 92 casos restantes están mayoritariamente localizados en los últimos años del siglo XVII y comienzos del XVIII, etapa en la que, por lo general, los testigos no suelen responder a cuestiones referidas a la pobreza de los progenitores. estrecheces económicas de los solicitantes, no hay duda de que ofrece unas pautas generales sumamente interesantes para perfilar de un modo más nítido las pautas de selección en el seminario (Tabla $\mathrm{n}$ o 2 ).

\section{TABLA $\cap 02$}

Circunstancias aducidas para la solicitud de las becas para pobres (1662-1831)

\begin{tabular}{|l|c|c|}
\hline Causa & Total & \% \\
\hline Padre difunto o inválido & 71 & 28,1 \\
\hline Pobreza familiar & 63 & 24,9 \\
\hline Familia numerosa & 60 & 23,7 \\
\hline Ambos padres difuntos & 33 & 13,0 \\
\hline Madre difunta & 26 & 10,3 \\
\hline Total & 253 & 100 \\
\hline
\end{tabular}

A.S.C.L. Libros de informaciones

Al igual que sucede en la mayoría de los centros ya estudiados, los criterios fijados por los diferentes textos normativos leoneses a la hora de definir el término "pobre" son, como hemos visto, un tanto difusos, no existiendo una delimitación económica clara. ${ }^{43}$ Atendiendo a la principal razón esgrimida a la hora de justificar la pobreza hemos distribuido las informaciones en seis grupos diferentes. La pérdida del cabeza de familia, con el consiguiente quebranto a la economía de la casa, fue la principal razón esgrimida por los solicitantes a la hora de optar a una beca en San Froilán: el $28,1 \%$ del total de estudiantes pobres respondían a este perfil. No olvidemos que en la época existía una estrecha relación entre pobreza y género, padeciendo el femenino una mayor predisposición. ${ }^{44}$ Esa circunstancia general, constatada también para el caso específico leonés en recientes estudios, ${ }^{45}$ explica estos resultados.

Por lo general, las mujeres viudas que acuden al amparo del seminario para poder ofrecer una educación a sus hijos, solían aducir la cortedad de los medios con los que contaban para hacer frente a los importantes gastos que generaban los estudios, tras la desaparición del cabeza de familia. Los

43 Una excepción a lo señalado la encontramos en el caso del seminario de Plasencia, en donde se exigía como requisito que los padres no tuvieran más de 50 ducados de renta al año. Martín Hernández, F. 1964: 214-215.

44 Rheinheimer, M. 2008. Pobres, mendigos y vagabundos. La supervivencia en la necesidad, 1450-1850: 41-44. Madrid: Siglo XXI; Dubert, I. 1992. Historia de la familia en Galicia durante la época moderna, 1550-1830: 117. A Coruña: Edicións do Castro; Reher, D. y Camps Cura, E. 1991. "Las economías familiares dentro de un contexto histórico comparado". Revista Española de Investigaciones Sociológicas 55: 65-91, 85.

45 Sirvan estos datos como ejemplo: en la ciudad de León el $74 \%$ de las 116 unidades familiares denominadas como pobres en el Catastro de Ensenada (1752) estaban regentadas por mujeres, porcentaje que era todavía más elevado en el caso de Astorga. Por su parte, en la villa de Sahagún el $17 \%$ de las mujeres cabezas de casa eran denominadas "pobres de solemnidad". Pérez Álvarez, Mํ. J. 2012. La familia, la casa y el convento. Las mujeres leonesas durante la Edad Moderna: 149 León: Universidad de León. 
testigos de la información abierta a D. Manuel Rodríguez, natural Santa Martín del Monte, señalaban que tanto los padres como los abuelos del aspirante habían sido "labradores de pan cojer" e hidalgos, viviendo razonablemente bien. Sin embargo, en aquellos momentos no dudaban en calificar a Manuela de Salas, su madre viuda, como "pobre de solemnidad". Esa precariedad económica, en no pocas ocasiones, se veía agudizada por la necesidad de mantener a una prole numerosa. Así le sucedía en 1678 a la madre de Benito de Córdoba, vecina del lugar de El Corral, en Santa Colomba de las Arrimadas, que acogía en su hogar al aspirante y a ocho hermanos más. Una situación muy semejante era la padecida por la madre de Matías Garrones, de Castroverde de Campos, que en 1795 señalaba la imposibilidad de costearle los estudios por sus escasos recursos y la precisión de alimentar a sus seis hijos. Tres años después la de José Baeza era calificada como pobre de solemnidad "por no conocérsela como no se la conoce vienes algunos" y tener que sostener "a tres hijos tiernos". 46

Otras veces, las beneficiadas de la labor caritativa del seminario eran mujeres viudas pertenecientes a sectores sociales más acomodados. En ese caso, también se podía esgrimir ciertas dificultades económicas aunque, evidentemente, con matices. En 1783 los testigos de la información confeccionada para la admisión como colegial de D. Marcelo García de Brizuela, natural de Fresnedo, afirmaban que, debido al fallecimiento de su padre, aquel "se alla bastantemente pobre". ${ }^{47}$ Pero no faltaron otros ejemplos en lo que junto a la precariedad económica aducida, y más o menos sincera, se señalaba también como argumento para la admisión de su hijo como colegial, la pérdida de reputación que conllevaría su no inclusión en el mismo. Así se lo hacía ver al obispo Cuadrillero Dña. Antonia Daza, viuda y vecina de León en 1793. En su petición señalaba que, de no admitirse a su hijo en el centro, no podría continuar sus estudios, "destinándose a familiar o sirviente en alguna ciudad donde les huviere". Ese mismo año los testigos de la información abierta a D. Francisco Garrido, natural de Villada, empleaban un argumento semejante, al señalar que "ha no lograr lo que intenta, se verá el pretendiente precipitado, si quiere continuar sus estudios, a estar en el servicio de alguna persona de honor y facultades". ${ }^{48}$

Si bien en la inmensa mayoría de los casos de este primer grupo el progenitor había fallecido, aparecen algunos ejemplos de padres que padecían algún tipo de minusvalía que les impedía mantener a su prole. Ese era el caso de Pedro Gutiérrez de Reyero, colegial que obtendrá en 1680 una beca de estudiante pobre, atendiendo a la ceguera de su padre.

Junto a la desaparición del cabeza de familia, existía un $13 \%$ de casos en donde la situación era todavía más grave, al hallarse el pretendiente huérfano de padre y madre. Ante esta extrema situación, en muchas ocasiones, se califica al solicitante como "pobre de solemnidad". Así sucedió en 1683 con Froilán de la Peña, vecino de la villa de Saldaña o

46 A.S.C.L., Libros no1, 3 y 6 de informaciones.

47 Su progenitor, D. Antonio García de Bizuela, había sido corregidor de la jurisdicción de Valdellorma y juez de apelaciones de la villa de Prioro y demás de aquella jurisdicción. A.S.C.L., Libro no 5 de informaciones.

48 A.S.C.L., Libro no 6 de informaciones. en 1690 con Bernardo Gutiérrez, de Joarilla de las Matas. Cuando en 1703 solicitaba la admisión en el colegio Santiago López de Vaíllo, vecino de la ciudad y sin amparo familiar alguno, pues los padres y abuelos habían fallecido, los testigos afirmaban que ante su desesperada situación "es caritativa obra ayudarle". Por su parte, en 1785 se aceptará en el seminario a D. José Fernández Escorriaza, vecino de León, con sus padres fallecidos y "sin medios algunos para subsistir en continuación de sus estudios". ${ }^{49}$ Más difícilmente creíble era el empleo del término pobre para huérfanos pertenecientes a reputados linajes del entorno leonés, como aconteció en 1789 con D. Manuel Villafañe, hijo de los fallecidos D. José de Villafañe y Dña. Isidora González, señores de la casa de la Vega. En su información los testigos también llegaban a calificarlo de ese modo, atendiendo a su discreta participación en la herencia paterna:

\begin{abstract}
"a cuias quentas y partijas le correspondió tan poco que aseguran no fue bastante para escluirle de la primer clase de verdaderos pobres, subsistiendo hasta aquí a expensas de la piedad de sus hermanos maiores, los que motivados de primeras obligaciones podrán, o tal vez, deberán suspender este socorro, añadiéndoseles otros dos hermanos más en igual situación". ${ }^{50}$
\end{abstract}

En este caso, como también hemos observado en el de las mujeres viudas procedentes de sectores sociales acomodados, posiblemente el término más adecuado sería el de pobre vergonzante, puesto que las dificultades de acceder a la educación superior irían en menoscabo de su posición en la sociedad. No obstante, un ejemplo tan palmario como el que acabamos de analizar, y que no es ni mucho menos excepcional, refleja con meridiana claridad las posibilidades que se abrieron dentro de las elites leonesas para beneficiarse de estos mecanismos. Esta concepción horizontal de la asistencia, que se podría resumir en el viejo refrán de que la caridad comienza por uno mismo, suponía uno de los elementos distintivos de todas las fundaciones de esta índole en la época y, por supuesto, también estaba presente en el seminario conciliar. No olvidemos que durante buena parte de su evolución histórica, la mesa capitular desempeñó un papel relevante en el gobierno del centro, por lo que resultaba relativamente sencillo que las mismas redes familiares de las elites que controlaban la designación de capitulares, pudiesen beneficiar a sus miembros en la distribución de becas en el colegio de San Froilán. ${ }^{51}$

Finalmente, en lo que atañe a la orfandad como criterio a la hora de solicitar una beca, los datos ofrecen un $10,3 \%$ de informaciones en las que se menciona el fallecimiento de la madre como causa de la petición. En la solicitud de ingreso, el progenitor suele hacer ver sus dificultades a la hora de poder hacer frente a la crianza y educación de su hijo debido a sus múltiples obligaciones. Por ejemplo, en 1673 el padre de Manuel Pérez de Bulnes, vecino de la villa de Potes, a pesar de su hidalguía y reconocer que poseía cierto patrimonio, aducía que la muerte de su esposa hacía

49 A.S.C.L., Libros no1, 2 y 5 de informaciones.

50 A.S.C.L., Libro no 6 de informaciones.

51 Pérez Álvarez, Mạ. J. y Martín García, A. 2009. “Elite, poder local y redes familiares en la ciudad de León durante el siglo XVII", en E. Soria Mesa y R. Molina Recio (eds.), Las élites en la Época Moderna: La Monarquía Española. Vol. II (Familias y redes sociales): 313-324. Córdoba: Universidad de Córdoba. 
necesario el ingreso de su vástago en el seminario, teniendo en cuenta que aún le restaban en su casa "diez hixos e hijas y muchos encargos". 52

Atendiendo a lo analizado hasta el momento, la orfandad suponía pues más de la mitad de las causas aducidas para obtener una beca de estudiante pobre en San Froilán: en concreto, el $51,4 \%$ del total de informaciones responden a esta tipología. Esa tragedia familiar motivaba la alteración del orden interno del hogar, provocando bien una brusca caída de sus ingresos y/o también evidentes dificultades a la hora de hacer frente a la crianza de una prole que solía ser numerosa.

Precisamente, la pobreza familiar o el excesivo número de hijos son las otras dos causas halladas en la documentación del centro a la hora de solicitar la beca. En el primer grupo, que significaba el $24,9 \%$ del total, estaban englobados aquellos padres que, por la cortedad de sus bienes, no podían hacer frente a los gastos que comportaba la educación de su vástago. Como ya hemos señalado en varias ocasiones, se trataba en estos casos de una pobreza limitada, pues incluso para acceder a las becas era necesario afrontar ciertos dispendios. Así, en 1817 el padre de Bernardo Malagón reconocía ser "de muy poco caudal para mantenerle en sus estudios", pero asumía "contribuir a su hijo aunque pobre con lo necesario en su clase de pobre en el relacionado seminario". ${ }^{53}$ Esa realidad se repite con frecuencia en los expedientes de todo el período; los testigos o los propios solicitantes, no señalaban, salvo excepciones, la ausencia de ingresos en el hogar sino la circunstancia de que éstos eran limitados y que, generalmente, se debían al trabajo personal del cabeza de familia. En 1788, el padre de Mauricio de Santiago, vecino de Mayorga, era, según los testigos, "de cortos caudales pues es labrador de una yunta de bueyes y toda la heredad que labra con ella es de arrenda y se be precisado el andar con ella para con su producto mantener su familia y lo poco o mucho que le gasta su hijo le haze falta a los demás de la casa". ${ }^{54}$

Esa situación de fragilidad económica, más que de pobreza propiamente dicha, era la que tenían que soportar aquellos cabezas de familia de estudiantes procedentes de hogares con un número elevado de miembros. Dicho sector, era en cifras globales y en porcentaje muy similar al anterior, suponiendo en $23,7 \%$ del conjunto de informaciones. En no pocas ocasiones los propios testigos corroboran el hecho de la existencia de un cierto patrimonio dentro del hogar que, no obstante, no puede sostener los dispendios que generarían los estudios del aspirante a colegial. El cura de Zugueros informaba en 1785 que el caudal del padre de José González "es mediano pero afecto a la sustentación de una crecida familia". Ese mismo año los testigos de la información de Manuel Álvarez, vecino de San Feliz de Torío, afirmaban que aun siendo nobles y contando con un mayorazgo, éste era de cortos caudales por lo que:

"el citado Don Juan tiene por suia propia una porción de hacienda vinculada con la que alimenta ocho hijos, sin los criados de la casa, con bastante estrechez, pero también es evidente que no se alla con medios para mantener

\footnotetext{
52 A.S.C.L., Libro no 1 de informaciones.

53 A.S.C.L., Libro no 8 de informaciones.

54 A.S.C.L., Libro no 6 de informaciones.
}

al referido Don Manuel Álvarez en sus estudios sin perjudicar en gran manera a los demás y desfalcar de todo punto su casa". ${ }^{55}$

En esa línea se mueven los testimonios presentados por la familia de Joaquín Rodríguez Burón, vecino de Pedrosa, en 1791 que subrayaban que el padre "aunque tiene y maneja algunos caudales no son vastantes sus rendimientos para mantener al pretendiente en sus estudios". El cabeza de familia, amén de poseer unos apreciables bienes raíces así como ganados mayores y menores, cobraba un sueldo como administrador del tabaco, por lo que, en efecto, distaba mucho de ser un menesteroso. ${ }^{56}$ Aun así, las obligaciones de mantener a seis hijos - cinco varones de corta edad y una mujer- dificultaban la situación. Algo semejante le sucedía, según los testigos, al padre de Juan Manuel Cañón, cirujano de Acebedo:

“El padre del referido D. Juan Manuel es de tan corto caudal que alguna heredad que cultiba no es propia sino de renta, que su producto es siempre mui escaso y que de ninguna manera puede sostener a su hijo en el estudio, pues para mantener a este hijo y otros siete en su compañía no tiene más facultades que la corta cantidad de maravedíes con que contribuye esta villa y pueblos agregados por asistir a los moradores en sus enfermedades". ${ }^{57}$

Ahora bien, también se localizan ejemplos de situaciones económicas mucho más endebles; en 1793 se otorgaba una beca a Martín Rodríguez natural de Viliella, cuyo padre era calificado como pobre de solemnidad "pues para los restantes ermanos, no tiene el dicho padre para el alimento cotidiano". Ocho años más tarde, el progenitor de Juan Montaña, de Fuentes del Ropel, que trabajaba como jornalero, era denominado por los testigos "pobre de solemnidad y cargado de hijos". ${ }^{58}$

Conviviendo con los estudiantes que gozaban de becas atendiendo a su precariedad económica, se encontraban los convictores que, como ya hemos señalado, eran aquellos que debían sufragarse los gastos que comportaban sus estudios y estancia en el centro. Ese era el caso de Martín Fernández de Ratia que en 1676 solicitaba entrar como pensionista en el seminario. A pesar de ser huérfano acreditaba que no necesitaba del auxilio de una beca pues "aunque su padre es muerto dejó bastante para sus alimentos". ${ }^{59}$ Como tuvimos la ocasión de comprobar al comienzo de este apartado, el peso específico de los convictores en el conjunto del estudiantado de San Froilán no comenzó a adquirir relevancia hasta la segunda mitad del siglo XVIII, ocupando ya un lugar preponderante durante las primeras décadas del XIX.

Las diferentes constituciones del seminario estipularon las obligaciones económicas que contraían con respecto al centro. Sin embargo, durante el siglo XVII y parte del XVIII el escaso número de estos colegiales supuso que dichas exigencias variasen con cierta frecuencia, siguiendo

55 A.S.C.L., Libro no 5 de informaciones.

56 Ciertamente los testimonios presentados en la información trataban de minusvalorar la riqueza de D. Joaquín, diciendo que sus bienes raíces "administrados importan quasi más los costos que el producto", el ganado generaba "escaso producto" y que las rentas del tabaco "han caído mucho últimamente".

57 A.S.C.L., Libro no 7 de informaciones.

58 A.S.C.L., Libro no 6 de informaciones.

59 A.S.C.L., Libro no 1 de informaciones. 
criterios un tanto difusos. Así, mientras que las constituciones de Caso señalaban la obligatoriedad de contribuir con 550 reales anuales y tres cargas de trigo, en 1698 Manuel Fernández Jincio se comprometía a abonar anualmente 500 reales, asumiendo la señalada cantidad de cereal, mientras que su compañero Damián de Oblanca, que ingresaba un año después, pagaba solamente 400 reales, amén del trigo referido. ${ }^{60}$ Esta relajación en las obligaciones económicas era reflejo de una gestión y una organización interna deficiente que tuvo además como consecuencia el hecho de que, a veces, las familias de los convictores desatendieran sus obligaciones para con el colegio. La falta de cuidado por parte de los administradores obligó al obispo D. José Gregorio de Rojas en 1704 a exigir que no se admitiesen nuevos pensionistas sin que presentasen la preceptiva escritura de obligación que los comprometiese legalmente a tener que contribuir anualmente con lo estipulado en las constituciones. ${ }^{61}$ Años más tarde, el obispo Cuadrillero trató de solucionar estos problemas, obligando a las familias a presentar un fiador y a pagar los gastos anuales en tres plazos: el primero a la entrada, el segundo a los seis meses y el tercero al finalizar el curso. Esta división tripartita, por otro lado, resultaba menos onerosa, dejando además el prelado la puerta abierta a un posterior incremento o disminución de las exigencias económicas según la coyuntura del momento. ${ }^{62}$

Por otro lado, no son infrecuentes los ejemplos de estudiantes que acceden a la categoría de convictor de un modo temporal, a la espera de que quede vacante alguna beca de pobre. Generalmente, los estudiantes entraban bajo el amparo de algún pariente clérigo, normalmente un tío, que se comprometía a su manutención pero que andaba presto a desvincularse de esa obligación económica en cuanto había posibilidad, merced a sus privilegiados contactos con las altas jerarquías diocesanas. Los ejemplos al respecto son abundantes, sobre todo a partir del siglo XVIII. Es el caso de Manuel García del Corral, que entró en el seminario como convictor en 1738 protegido por un tío sacerdote y que, tres años después, solicitaba el cambio de categoría al no poder su protector seguir sosteniéndole "por lo calamitoso de los tiempos". Ese mismo año, el tío de Santiago Triados señalaba en su solicitud que asumía los gastos de su sobrino mientras no quedase una beca de pobre vacante, puesto que las obligaciones con su familia le impedían mantenerlo indefinidamente. La existencia de esa práctica consentida queda fielmente reflejada en el caso de Santiago de la Torre Iglesias. En noviembre de 1770 el padre del estudiante, D. Santos de la Torre, solicitaba su ingreso en el seminario, asumiendo los gastos que comportaba su estancia. Sin embargo, año y medio más tarde escribía una carta al obispo D. Baltasar de Yusta Navarro solicitando su conversión en colegial pobre. D. Santos en el escrito aseguraba que su decisión de ingresar a su vástago como convictor en San Froilán se produjo "en bista de ziertos consejos que

60 A.S.C.L. Constituciones de Fr. Andrés de Caso, Cap. III; Libro no 1 de informaciones.

61 A.S.C.L., Libro de erección, dotación y agregación.

62 En las constituciones de Cuadrillero los estudiantes pensionistas estaban obligados a contribuir anualmente con 50 ducados y 12 fanegas de trigo, además de tener que traer sus vestidos, hábito y beca que había de pagar a su costa. me dieron de que pagando medio año primero era fácil el conseguir que se le mantubiese de limosna". ${ }^{63}$ El propio rector del seminario informaba al obispo, dos años más tarde, sobre la frecuencia de estas prácticas, que consideraba muy gravosa para las arcas del centro. ${ }^{64} \mathrm{~A}$ pesar de estos lamentos, tales comportamientos no disminuyeron en los años inmediatamente posteriores. Será la intensa labor reformadora del obispo Cuadrillero en el último tercio del siglo la que logre terminar con esta situación.

En otras ocasiones, en el caso de que una familia pretendiese el ingreso de varios hermanos en el centro, se lograba que uno de ellos fuese admitido como pobre bajo la condición de que el segundo accediese en condición de convictor. Es lo que sucedió en 1759 con los hermanos Manuel y Francisco Antonio Valbuena y Córdoba, vecinos de la Sota de Valderrueda. Gracias a las gestiones de su tío, que era el cura párroco de El Cegoñal, el primero se beneficiaba de una beca de pobre mientras que el segundo había de pagar lo establecido, obligación que asumía el propio clérigo. Un caso similar se produjo tres años más tarde con los hermanos Francisco y Sebastián Sancho, asumiendo en este caso los gastos del segundo un tío tonsurado. Teniendo en cuenta tanto estas prácticas como las anteriormente analizadas, parece evidente que el porcentaje de alumnos que acabaron beneficiándose de una beca para estudiantes pobres en el seminario leonés fue incluso superior a los porcentajes que arrojan las informaciones.

\section{REQUISITOS DE ENTRADA Y PROCEDENCIA SOCIO-ECONÓMICA DE LOS COLEGIALES}

Tanto los aspirantes a una beca de pobre como los pensionistas estaban obligados a cumplir una serie de requisitos para ingresar en el colegio de San Froilán muy similares a los constatados para otros centros de esta categoría en la época. Tales exigencias fueron fijadas en 1606 por las primeras constituciones aprobadas por Fr. Andrés de Caso, sufriendo después leves alteraciones. A la legitimidad, requisito estipulado en las disposiciones conciliares, se añadía la necesidad de reunir unas condiciones morales adecuadas y una natural predisposición para el estado sacerdotal, con la necesaria repugnancia a las malas costumbres y vicios indeseables. ${ }^{65}$ Del mismo modo, era imprescindible acreditar que el aspirante no sufriera ningún mal o padecimiento físico o psíquico que pudiera impedir el posterior ejercicio de sus funciones sacerdotales o una enfermedad contagiosa que pusiera en peligro a sus compañeros. ${ }^{66}$

63 A.S.C.L., Libro no 4 de informaciones.

64 "No puedo menos de decir que muchos desean entrar de conbíctores con la esperanza de poder lograr después de algún tiempo el alibio de pasar a beca de pobre". A.S.C.L., Libro no 4 de informaciones.

65 Fr. Andrés de Caso señalaba que los colegiales habían de ser honestos, de buenas costumbres y sin vicios. Por su parte D. Bartolomé Santos de Risoba los veía "buenos y blandos, naturales dóciles y ábiles para los estudios". A.S.C.L., Constituciones de Fr. Andrés de Caso, Cap. III; Constituciones de Bartolomé Santos de Ricoba, Cap. II.

66 "Han de ser sanos y robustos para llegar las cargas del colegio". A.S.C.L., Real Provisión por la que se aprueban las constituciones o estatutos para el régimen y gobierno de colegio seminario de San Froilán. Cap. XIII. 
Un aspecto ineludible en la época era la inevitable exigencia de limpieza de sangre, práctica característica del mundo ibérico, de la que, por supuesto, tampoco quedó al margen el centro educativo leonés. A este respecto Fr. Andrés de Caso, siendo consciente de que este requisito no se hallaba presente en las disposiciones conciliares, exhortaba a los informadores a que lo hicieran con la mayor cautela posible:

"y porque el dicho concilio no pide expresamente la dicha limpieza, el obispo en las elecciones que hiçiere de rector y collegiales con el maior secreto que fuere posible sin escribir se informe de las calidades que tienen los opositores al dicho seminario para que conforme a ellas haga election de las personas que más convengan". ${ }^{67}$

Esta tibia recomendación o la ausencia de referencias al respecto en las posteriores constituciones de D. Bartolomé Santos de Risoba, no debe hacernos suponer una relajación en estas cuestiones para el caso leonés. ${ }^{68}$ De hecho, desde las primeras informaciones conservadas de pleno siglo XVII, se incluye entre las preguntas del interrogatorio la constatación de la limpieza de sangre del aspirante, tanto por línea paterna como materna. Las tardías constituciones del obispo Cuadrillero de 1792, dejaban de nuevo estipuladas tales exigencias, que, por cierto, se mantuvieron vigentes hasta, al menos, las décadas centrales del siglo XIX.

En cuanto al lugar de naturaleza de los aspirantes existía una clara distinción entre los colegiales pobres y los pensionistas. Mientras que los primeros debían acreditar ser naturales del obispado, en los segundos este requisito desaparecía, atendiendo a la contribución económica que realizaban. Por el contrario, tanto unos como otros debían cumplir con los límites de edad estipulados, exigencias que mudaron en varias ocasiones a lo largo del período. Así, si en las primeras constituciones se señalaba que la edad de los colegiales debía estar comprendida entre los doce y los veinte años, en las de 1646 se restringía notablemente este marco temporal, estableciéndose entre los doce y los catorce, aumentándose hasta los dieciséis a finales del siglo XVIII. ${ }^{69}$

Como se puede comprobar en los datos que arrojan los cálculos de la edad media por etapas, existe un retraso en la edad de acceso al seminario a partir de la segunda mitad del siglo XVIII que, en gran medida, responde a los nuevos criterios impuestos en las constituciones del obispo Cuadrillero y que, de hecho, se llevaban aplicando unos años antes de la aprobación oficial de este nuevo texto normativo. De este modo, mientras que durante las últimas décadas del XVII y primera mitad del XVIII, tanto la edad media como la modal de los colegiales ingresados se hallaba entre los trece y los catorce años, a partir de entonces aumentó hasta situarse entre los quince y los dieciséis (Tabla no 3)..$^{70}$

${ }^{67}$ A.S.C.L., Libro de erección, dotación y agregación, Constituciones de Fr. Andrés de Caso, Cap. III.

68 Martín Hernández, F. 1964: 212.

69 A.S.C.L., Libro de erección, dotación y agregación, Constituciones de Fr. Andrés de Caso, Cap. III; Constituciones de Bartolomé Santos de Risoba, Cap. II; Real Provisión por la que se aprueban las constituciones o estatutos para el régimen y gobierno de colegio seminario de San Froilán, Cap. XIII

70 Disponemos de 538 informaciones en la que se estipula la edad de colegial, lo que supone un $87,4 \%$ del total. En la gran mayoría de las ocasiones, además de los testimonios de los testigos, que suelen ser bastante certeras, se adjunta en el expediente una copia de la partida de bautismo, por lo que el grado de fiabilidad de los resultados obtenidos es elevado.
TABLA nㅇ 3

Edad de los colegiales de San Froilán (1662-1831)

\begin{tabular}{|l|c|c|}
\hline Años & Edad Media & Edad Modal \\
\hline $1662-1700$ & 13,8 & 14 \\
\hline $1701-1750$ & 13,6 & 13 \\
\hline $1751-1800$ & 15,7 & 16 \\
\hline $1801-1831$ & 15,3 & 15 \\
\hline Total período & 15,1 & 16 \\
\hline
\end{tabular}

A.S.C.L. Libros de informaciones

Aun así, estas exigencias en cuanto a la edad podían sortearse con cierta facilidad, sobre todo durante el prolongado período de decadencia del seminario que corresponde con la segunda mitad del siglo XVII y la primera del XVIII. De hecho, en la primera etapa analizada, la situada entre 1662 y 1700 , el 31,2\% de los alumnos ingresados incumplían los requisitos sobre edad, en la mayoría de las ocasiones más por exceso que por defecto. Este porcentaje de incumplimiento aumentó todavía más durante entre 1701 y 1755 , hasta situarse en el 50,9\% del total. A partir de entonces no hizo más que reducirse hasta quedar fijado en el $17,5 \%$ en las tres primeras décadas del siglo XIX, porcentaje, por otro lado aún un tanto elevado debido a los desajustes provocados por el período bélico contra los franceses.

El último de los requisitos estipulados en las constituciones estaba relacionado con los criterios de carácter intelectual necesarios para acceder al centro. En este aspecto, las exigencias aumentaron con el tiempo, motivadas por el mayor nivel educativo que adquirió el seminario a finales del XVIII. De este modo, si en las constituciones de 1606 solamente se exigía a los aspirantes demostrar su dominio de la lectura, escritura y doctrina cristiana a través de una prueba de acceso, en tiempos de Cuadrillero los criterios se elevaron, al ser examinados rigurosamente de gramática. ${ }^{71}$ Las nuevas características del seminario, que había pasado de ser en la práctica un pequeño colegio de acogida de estudiantes pobres a un centro vinculado a la Universidad de Valladolid explica estos cambios.

Para finalizar, hemos querido realizar una aproximación a la realidad socio-económica de los alumnos del seminario tomando como base la información aportada por sus expedientes de entrada. Partimos de la base de que estamos ante una información limitada por dos razones: en primer lugar porque el mayor volumen de datos procede de los momentos de esplendor del centro $y$, en segundo, porque existe una evidente descompensación entre los colegiales pobres y los pensionistas, habida cuenta de que los segundos, al no tener que demostrar los limitados ingresos de su familia en muchas ocasiones no hacen referencia a la procedencia socio-económica de sus progenitores. En consecuencia solamente en el $29,2 \%$ de las informaciones contamos con referencias al respecto, suponiendo en el conjunto de los

71 A.S.C.L., Real Provisión por la que se aprueban las constituciones o estatutos para el régimen y gobierno de colegio seminario de San Froilán, Cap. XIII. 
pobres un $34,5 \%$ y en el de los pensionistas un $22,5 \% .^{72}$ Por otro lado, del total de 180 casos localizados con información al respecto, solamente 25 proceden de las informaciones anteriores a 1750 , apenas un $13,8 \%$. Estas deficiencias de la fuente nos obliga a movernos en este campo con cierta cautela, entendiendo que, desde luego, los resultados pierden credibilidad a medida que nos sumergimos en los tiempos más remotos del colegio o que analizamos el sector convictor. De todas maneras, se trata de unos datos que, al menos, deben mostrarnos unas tendencias generales, sobre todo desde 1750 en adelante (Tabla no 4).

TABLA nㅇ 4

\section{Procedencia socio-económica de los progenitores de los} colegiales (1662-1831)

\begin{tabular}{|l|r|r|r|r|r|r|}
\hline Profesión & Pobre & \multicolumn{1}{c|}{$\%$} & Convictor & \multicolumn{1}{c|}{$\%$} & \multicolumn{1}{c|}{ Total } & \multicolumn{1}{c|}{$\%$} \\
\hline Labrador & 39 & 32,8 & 3 & 4,9 & 42 & 23,3 \\
\hline Profesional del derecho & 13 & 10,9 & 25 & 41,0 & 38 & 21,1 \\
\hline Escribano o administración & 18 & 15,1 & 13 & 21,3 & 31 & 17,2 \\
\hline Médico o cirujano & 14 & 11,8 & 4 & 6,6 & 18 & 10,0 \\
\hline Noble & 4 & 3,4 & 11 & 18,0 & 15 & 8,3 \\
\hline Comerciante & 6 & 5,0 & 3 & 4,9 & 9 & 5,0 \\
\hline Pobre de solemnidad & 8 & 6,7 & - & - & 8 & 4,4 \\
\hline Artesano & 7 & 5,9 & 1 & 1,6 & 8 & 4,4 \\
\hline Enseñanza & 6 & 5,0 & 1 & 1,6 & 7 & 3,9 \\
\hline Jornalero & 4 & 3,4 & 0 & 0,0 & 4 & 2,2 \\
\hline TOTAL & 119 & 100,0 & 61 & 100,0 & 180 & 100,0 \\
\hline
\end{tabular}

A.S.C.L. Libros de informaciones

La primera impresión que arrojan los datos es la importancia desempeñada por lo que podemos denominar las "profesiones liberales", incluyendo en este término a los profesionales del derecho, los escribanos y oficiales de las administración real, señorial o religiosa, los médicos y cirujanos así como los profesionales de la enseñanza. En conjunto estos sectores representaban el 52,2\% del total de los expedientes con información al respecto, procediendo en su mayoría del mundo urbano o semiurbano de la diócesis. De estos cuatro grupos, los integrantes de los dos últimos obtenían mayoritariamente becas para pobres, circunstancia lógica teniendo en cuenta la limitada consideración social que tenían estos oficios en la época, amén de los cortos ingresos que su ejercicio comportaban. ${ }^{73}$

72 En concreto, contabilizamos 180 informaciones que aportan referencias de un total de 616 vaciadas.

73 En 1791 el padre de Dionisio Reyero, natural de Burón, decía ser de cortos caudales, "de modo que para el sustento de su muger y familia se be en la necesidad y precisión de ganarlo con su sudor y trabajo personal", pues no poseía ni rentas ni hacienda, sustentándose "en el penoso oficio de cirujano de este partido". Por su parte, en 1798, el progenitor de Ramón Pérez, D. Lucas Pérez, era calificado en la información como pobre, a pesar de ser el catedrático de los estudios públicos de San Feliz de Torío. A.S.C.L., Libro no 6 de informaciones.
Por el contrario, un número significativo de abogados de las últimas décadas del siglo XVIII y de comienzos del XIX, confiaron a sus hijos a la tutela del colegio de San Froilán contribuyendo para ello con las exigencias económicas que señalaba el centro. Algo similar sucedió con los escribanos u oficiales de las diferentes administraciones, aunque en este caso, no fueron infrecuentes las concesiones de becas de pobres, muchas veces motivadas por la vinculación del padre del estudiante a la administración diocesana o capitular. ${ }^{74}$

Al margen ya de los reseñados, los hijos de labradores desempeñaban también un papel relevante en el contexto general del estudiantado de San Froilán, alcanzando un 23,3\% del total. A diferencia de los anteriores grupos, en este caso, como no podía ser de otro modo, la procedencia es fundamentalmente rural, vinculándose a sectores más o menos acomodados que teniendo una hacienda aceptable se beneficiaban del programa de becas del seminario como salida natural para alguno de sus hijos. En muchas ocasiones estos labradores, a menudo hidalgos, eran aquellos padres que alegaban un número excesivo de hijos, y no una verdadera pobreza, para poder optar a la concesión de una beca. ${ }^{75}$ Por su parte, la nobleza rentista del entorno leonés, ${ }^{76}$ como también sucedía con los letrados, puso sus miras en el seminario una vez concretizado el ambicioso plan de reformas acometido por D. Cayetano Cuadrillero. A partir de entonces el centro, como ya hemos podido comprobar, fue abandonando paulatinamente su vocación asistencial para convertirse en una institución de estudios superiores de innegable atractivo para las elites. ${ }^{77}$ Aunque en este grupo priman los estudiantes pensionistas, también existen pobres que, generalmente por motivos de orfandad, se ven beneficiados por unos mecanismos de solidaridad horizontal que solían funcionar con presteza.

El resto de sectores socio-económicos jugaba ya un papel bastante discreto en el conjunto general de ingresos, comenzando por los denominados "pobres de solemnidad" que respondían, más bien, a la imagen del pobre

74 En 1693 Pedro Ibañez, asistente en la contaduría de la mesa capitular, lograba obtener del rector del seminario una beca para un hijo suyo. Estas redes clientelares no se restringían exclusivamente a los círculos administrativos, sino que otros servidores, bien del obispo o bien del cabildo, podían también beneficiarse de esa proximidad al poder. Ese fue el caso en 1680 del estudiante José de Robles, huérfano de Mateo Robles, platero y "criado que fue de Vuestra Señoría" o, en 1750, de Miguel de Neira cuyo abuelo había sido músico de la catedral. A.S.C.L., Libros $n=1$ y 2 de informaciones.

75 En 1662 los padres de Lucas Alcalde eran unos hidalgos que no poseían más bienes "que sus tratos y granxerías". En 1732 cuando el progenitor de D. Fernando Pérez de Bulnes, natural de la provincia de Liébana, solicitaban una beca, decían no tener lo necesario para mantenerlo en sus estudios "por el preciso gasto de su casa e la manutención de su familia que es larga y de treze hijos legítimos, sin otros cinco que se han muerto, y criados precisos para las labores del campo". Tiempo más tarde, en 1816, el padre del seminarista de Oceja Nicolás Rodríguez señalaba que "aunque es y goza del estado noble hijosdalgo, sus facultades son tan cortas y todas se reducen a una pobre labranza según son todas las de la montaña, con la que y su sudor con mucha estrechez mantiene a cinco hijos además del espresado D. Nicolás". A.S.C.L., Libros no 1, 2 y 6 de informaciones.

76 Hemos diferenciado este sector del de aquellos labradores que aun teniendo reconocida su hidalguía sostenían sus casas y haciendas "con su sudor natural", parafraseando la expresión más comúnmente empleada en las informaciones.

77 Así sucede en 1804 con los señores de Villamañán que envían a su hijo D. Mariano Baeza a cursar estudios en el centro leonés. A.S.C.L., Libro no 6 de informaciones. 
vergonzante; esto es, algún miembro de los sectores acomodados de la sociedad que por avatares del destino, frecuentemente la orfandad, acababan sumidos en una situación delicada. Fuera de ellos, el número de integrantes del comercio o del artesanado es reducido. En el primer caso, se trata, más bien, de trajinantes o comerciantes al por menor que pueden beneficiarse de los auxilios ofertados por el seminario, mientras que los más pudientes siguen la estela de la nobleza o de los profesionales del derecho. Finalmente, tanto los hijos de los artesanos como de los jornaleros se hallan en una situación económica más precaria que los hace acreedores de las becas del seminario.

\section{CONCLUSIONES}

La combinación del estudio cuantitativo con el cualitativo de la documentación generada por el seminario conciliar de San Froilán de León nos ha permitido analizar el nacimiento, desarrollo y las dimensiones sociales de una institución educativa estrechamente unida al proceso reformista tridentino. Tras unos inicios dubitativos, a partir de la segunda mitad del siglo XVII el centro acabó consolidándose, aunque las limitaciones de sus rentas no le permitieron cumplir con las ambiciosas expectativas puestas en él por parte de sus fundadores. Habrá que esperar al último tercio del siglo XVIII para que el seminario conciliar se convierta, verdaderamente, en un centro educativo de alto nivel, con un cuadro docente adecuado y unas rentas suficientes. Paralelamente a estas transformaciones, fue desprendiéndose de su carácter asistencial, vinculado al auxilio a estudiantes pobres, para convertirse en una institución de referencia a nivel provincial, lo que motivó el paulatino incremento de los estudiantes pensionistas procedentes de los sectores más pudientes de la sociedad.

Por otra parte, la supuesta pobreza que alegaban las familias de los estudiantes que optaban a una beca distaba mucho del concepto de pobreza de solemnidad imperante en la época. La imposibilidad de las clases populares para acceder al sistema educativo, las obligaciones económicas a las que se comprometían las familias en el caso de lograr su objetivo y la existencia de importantes redes clientelares, condicionaban los ingresos. En general, los estudiantes pobres que accedieron al seminario eran hijos de los integrantes de los sectores acomodados de la sociedad leonesa del momento, que bien por circunstancias demográficas -la orfandad o el excesivo número de hermanos-, bien por cuestiones meramente económicas o por la combinación de ambos factores se veían en la tesitura de solicitar el auxilio de la institución. Aunque no hay duda de que a veces esa solicitud de caridad era sincera, también lo es que en no pocas ocasiones las estrechas relaciones con las autoridades eclesiásticas agilizaban sobremanera los trámites.

\section{BiBLIOgRAFÍA}

Alonso, P. M., Casado, M. y Casado, F. J. 2004. El concilio de Trento y los colegios de las "naciones" de la Universidad de Alcalá de Henares: el Colegio Menor "De León" (1586-1843). Madrid: Dykinson.
Barreiro Mallón, B. 2003. “Clero secular e estudiantes na diócese de Santiago durante o século XVIII". Revista Galega do Ensino 36: 81-115.

Bartolomé Martínez, B., Utrilla Soria, P. y Yagüe Durán, J. 1999. “Los autos de información y pruebas de pureza de sangre de los alumnos del colegio seminario en el Burgo de Osma (1617-1851)". Celtiberia 93: 365-398.

Dubert, I. 1992. Historia de la familia en Galicia durante la época moderna, 1550-1830. A Coruña: Edicións do Castro.

Fernández Conde, M. 1948. España y los seminarios tridentinos. Madrid: CSIC/Instituto "Enrique Flórez".

Fernández Terricabras, I. 2000. Felipe II y el clero secular. La aplicación del Concilio de Trento. Madrid: Sociedad Estatal para la Conmemoración de los Centenarios de Felipe II y Carlos V.

García Cárcel, R. y Palau i Orta, J. 2006. "Reforma y Contrarreforma católicas", en A. L. Cortés Peña (Coord.), Historia del Cristianismo III. El Mundo Moderno: 187-226.

Martín Hernández, F. 1964. Los seminarios españoles. Historia y pedagogía I (1563-1700). Salamanca: Ediciones Sígueme.

Martín Hernández, F. y Martín Hernández, J. 1973. Los seminarios españoles en la época de la Ilustración. Ensayo de pedagogía eclesiástica en el siglo XVIII. Madrid: CSIC/Instituto Enrique Flórez.

Mas Galvañ, C. 2004. "Tres seminarios españoles del Setecientos: Reformismo, Ilustración y Liberalismo". Cuadernos de Historia Moderna. Anejos 3: 163-200.

Pérez Álvarez, Mạ. J. 2009. "Mortalité et hygiène dans la ville de León au cours de l'époque moderne". Annales de Bretagne et des Pays de L'ouest 116-2: 55-79.

Pérez Álvarez, Mạ. J. 2012. La familia, la casa y el convento. Las mujeres leonesas durante la Edad Moderna. León: Universidad de León.

Pérez Álvarez, Mạ. J. y Martín García, A. 2009. “Elite, poder local y redes familiares en la ciudad de León durante el siglo XVII", en E. Soria Mesa y R. Molina Recio (eds.), Las élites en la Época Moderna: La Monarquía Española. Vol. II (Familias y redes sociales): 313-324. Córdoba: Universidad de Córdoba.

Polo Rodríguez, J. L. 1991. "Estudiantes manteístas salmantinos en la Universidad de Salamanca de la primera mitad del siglo XVIII". Studia Historica. Historia Moderna, 9: 23-41.

Reher, D. y Camps Cura, E. 1991. "Las economías familiares dentro de un contexto histórico comparado". Revista Española de Investigaciones Sociológicas 55: 65-91.

Rheinheimer, M. 2008. Pobres, mendigos y vagabundos. La supervivencia en la necesidad, 1450-1850. Madrid: Siglo XXI.

Rodríguez San Pedro Bezares, L. E., Alejo Montes, F. J. y Polo Rodríguez, J. L. 2004. "Matrículas y grados, siglos XVI-XVIII", en Rodríguez San Pedro Bezares, L. E. (Coord.), Historia de la Universidad de Salamanca: Vol. 2, 607-663. Salamanca: Universidad de Salamanca.

Sánchez González, J. 2009. "El obispo Cuadrillero y el Seminario Conciliar de San Froilán de León”. Studium legionense. 50: 299-322.

Sobaler Seco, Mạ. A. 2004. "Los estudiantes leoneses en la Universidad de Valladolid durante la Edad Moderna (ss. XVI-XVIII)", en J. Paniagua Pérez (Coord.), Hacia la Universidad de León: Estudios de Historia de la Educación en León: 193-220. León: Universidad de León.

Torremocha Hernández, M. 1986. “La matriculación estudiantil durante el siglo XVIII en la Universidad de Valladolid". Investigaciones históricas: Época moderna y contemporánea 6: 39-74.

Vergara Ciordia, J. 1986. "Factores condicionantes del desarrollo de los seminarios conciliares en el reinado de Carlos III", en Iglesia y educación en España. Perspectivas históricas. IV Coloquio de Historia de la Educación: 292-401. Palma de Mallorca: Universitat de les Illes Balears.

Vergara Ciordia, J. 1997. "La actitud de la jerarquía eclesiástica ante el fenómeno de la secularización docente ilustrada”, en J. Vergara Ciordia (Coord.), Estudios sobre la secularización docente en España: 61-95 Madrid: UNED.

Villacorta Rodríguez, T. 1974. El cabildo de la catedral de León. Estudio histórico-jurídico, siglos XII-XIX: 464-477 León: Centro de Estudios e Investigación "San Isidoro". 